\title{
Una poética política: Sobre Crónica de un niño solo y Nazareno Cruz y El Lobo de Leonardo Favio
}

\author{
Symphony of an aesthetic: about Crónica de un niño solo and Nazareno Cruz y el \\ lobo by Leonardo Favio
}

\author{
Mariana Baranchuke \\ Paula Rodriguez Marino \\ Professora de la Carrera de Ciencias de la Comunicación, Facultad de Ciencias Sociales, Universidad de \\ Buenos Aires. \\ E-mail:prmarino@uolsinetics.com.ar.
}

\section{Resumen}

El análisis de Crónica de un niño soloy de Nazareno Cruz y el lobo demuestra que la filmografia de Leonardo Favio es una obra única y que postula una poética política. A partir de este objetivo analizamos la presencia de una poética del espacio y de una poética del tiempo en los dos filmes señalados. Los conceptos de "soledad", "ley" y "desamparo" y "lealtad/traición", así como la puesta en escena articulan estas poéticas espaciotemporales.

Palabras clave: cine - estética - politico

Introducción una filmografia en los márgenes

Existen diversas modalidades de análisis entre quienes teorizan sobre la filmografía de Leonardo Favio. En este trabajo, frente a otras concepciones, concebimos a la filmografía de Favio como una totalidad (Farina, 1993; Wolf, 1993), sin suponer que la unicidad de la obra está dada, ni que el arte es del orden de lo inefable. Para sustentar esta propuesta analizaremos temas (la

'Producción: Luis Di Stefano. Guión: Zuhair Jury y Leonardo Favio. Fotografia: Ignacio Souto. Cámara: Enrique Filipelli. Música: Domenico Cimarosa y Benedetto Marcello. Blanco y Negro. Duración: 77'. Blanco y Negro. Intérpretes: Diego Puente, Tino Pascali, Oscar Espíndola, Victoriano Moreira y Leonardo Favio, entre otros.

\section{Producción: Choila Producciones} Cinematográficas. Guión: Zuhair Jury y Leonardo Favio. Fotografia: Juan José Stagnaro. Cámara: Carmelo Lobotrico. Música: Juan José Caffi y Jorge Candia. Color. Duración: '88. Intérpretes: Juan José Camero, Marina Magali, Alfredo Alcón, Nora Cullen y Lautaro Murúa, entre otros.

${ }^{3}$ La primera expiriencia de Leonardo Favio (Fuad Jury) como director que es el cortometraje $E I$ amigo (1960) no se induye en estas periodizaciones. soledad, la ley, el desamparo y el eje lealtad/traición), así como procedimientos formales (movimientos de cámara, tipo de montaje y uso de los planos) que acercan a Crónica de un niño $s o^{\prime}$ con Nazareno Cruz y el lobo ${ }^{2}$ adaptación basada en el radioteatro homónimo de Juan Carlos Chiappe. El título de este trabajo retoma la concepción sinfónica que se desprende de toda la obra de este director que piensa el cine como una composición musical. Asimismo, analizaremos las concepciones y percepciones de la espacialidad y de la temporalidad como dos ejes que nos permiten explicitar los componentes de una misma poética.

Otra concepción sobre la obra de Favio (Oubiña y Aguilar, 1993) señala dos etapas claramente diferenciadas; la primera más cercana al neorrealismo, con fuertes marcas bressonianas que caracterizaría a sus tres primeros filmes, en blanco y negro: Crónica de un niño solo, Este es el romance del Aniceto y la Francisca, de cómo quedo trunco, comenzó la tristeza y unas pocas cosas más (1967) y El dependiente (1968). Mientras que la segunda, sería la del cine-espectáculo - de la imagen-acción: Juan Moreira (1973), Nazareno Cruz y el lobo, Soñar, Soñar y Gatica, el mono (1992). Por último, análisis más ligados a la crítica de espectáculos dividen la producción de Favio en tres momentos: el período blanco y negro, un segundo momento compuesto por Juan Moreira y Nazareno Cruz y el lobo, cerrando el ciclo con los films Soñar, soñar y Gatica, el mono y el tercer momento en el que ubican a Perón: Sinfonia del sentimiento $(1999)^{3}$.

En relación a su adscripción a posiciones estético-políticas en la cinematografía nacional, la denominación de "cineasta de los márgenes" se aplica a Favio desde el inicio de su filmografía hasta sus obras más comerciales. A mediados de los años ' 60 hay dos posiciones estéticopolíticas destacables: una ligada a la lógica comercial y otra, la llamada generación del ' 60 también denominada por los críticos "Nuevo cine Argentino" (Manuel Antín, Rodolfo Kuhn, David José Kohon), un cine con fuerte referencia a la nouvelle vague y que tiene a Leopoldo Torre Nilsson y a José Martínez Suárez unas 
de sus referencias más importantes en el ámbito nacional. Hacia mediados de la década, cobran importancia el cine de intervención política ${ }^{4}$ y otros filmes como, por ejemplo, Shunko (1960) de Lautro Murúa, en los que se destaca la "conciencia social" y se aborda la pobreza y la exclusión como "problema sociológico" (Aguilar, 1994: 33).

El cine de Leonardo Favio no pertenece a ninguna de estas vertientes y tendrá una deuda estética con Torre Nilsson aunque al igual que los exponentes del cine de intervención política presentará un mundo donde los pobres son centrales. Favio es un out sider, una figura difícil de encuadrar, que escapa a los etiquetamientos. Favio crea y produce desde los bordes. No es un marginal de la industria pero tampoco un integrado. No hay compasión, no hay exaltación intelectual de la pobreza en la filmografía de Favio. Sus films carecen de una contemplación dulcificada de la pobreza, la suya es una mirada que padece, se salva o se hunde con las criaturas que crea.

\section{Una poética del espacio}

Posiblemente el tratamiento del espacio en los dos films de referencia constituya el ámbito de mayor divergencia entre ambos. Especialmente lo que hace al tratamiento de los espacios cerrados. Mientras que en Crónica de un niño solo se relacionan a lo opresivo, al encierro en Nazareno Cruz y el lobo son seguros (la casa de la madrina de Nazareno) o bien presentan una opción para el personaje (el descenso al infierno le da a Nazareno la posibilidad de cambiar su destino).

En cambio en la relación que se establece con los espacios abiertos encontramos mayor puntos de contacto: la enorme cantidad de secuencias y planos del campo en Nazareno Cruz y el lobo acompañan al estado emocional de los personajes pero sobre todo, Favio los utiliza para quebrar cierta visión idealizada, bucólica de lo campestre y de la naturaleza en general. Plantea un tono de amenaza latente y real en los espacios abiertos, una sensación semejante ya había aparecido en Crónica de un niño solo. La violación del amigo de Polín ocurre en un lugar plácido, cerca del río y Favio utiliza la elipsis para escenificar la violencia. También la villa miseria a la que va Polín en su huida es un espacio abierto mostrado con planos generales que se detienen en los techos de chapa pero sin hacer foco en la precariedad. Así, la villa miseria se contrapone a los vericuetos del reformatorio pero ese espacio abierto no responde a una visión idílica, la ley puede entrometerse e imponer su lógica. El espacio es abierto pero al mismo tiempo se va cerrando a través de planos generales en picado de techos de chapa puertas, pasillos, hendiduras, ventanas, rejas: el espacio está geometrizado, lo que da una sensación de encierro. Esa geometrización se agudiza en las escenas del correccional. Un espacio geometrizado (Aguilar y Oubiña, 1993) que conduciría a concluir, erróneamente, que estamos frente a un film realista y ascético. Pero la poética del espacio de Favio no es ascética ${ }^{5}$. La poética espacial que construye es barroca por la variedad de técnicas de montaje, por el encuadre y por la angulación de la cámara (planos medios en picado y contrapicado del reformatorio y de la iglesia en el inicio del filme, primeros planos en contrapicado del otro niño que vence Polín en una pelea) y la cantidad de objctos y personajes (el celador en un esquina del cuadro, los parientes en el piso inferior y Polín en la escalera) que pueblan el cuadro.

Por su parte, en Nazareno Cruz y el lobo los encuentros amorosos de Nazareno y Griselda son siempre a cielo abierto, la trasgresión del romance de los personajes se evidencia por las tomas a través del follaje, ese espacio abierto es fuente de amor y de muerte, la velocidad que le imprime el travelling así lo muestra y, al igual que en Crónica de un niño solo lo geometriza, lo encierra. La persecución de Nazareno es a campo traviesa, los mismos pobladores que habían bromeado con Nazareno por la maldición del lobizón salen a cazarlo. El espacio abierto conduce directamente
${ }^{4}$ Nos referimos al Grupo Cine Liberación (Gerardo Vallejo, Fernando Solanas, Octavio Getino y Nemesio Juárez) yal Cine de la Base (Raymundo Gleyzer, Nerio Barberis y Alvaro Melián).

${ }^{5}$ En Crónica de un niño solo hay austeridad en la producción y en la ausencia de grandes acciones. La mirada y el encuadre son barrocas al igual que en Nazareno Cruzyel lobo (Farina, op.cit: 17). 
a los personajes a su propio final trágico: la muerte para Nazareno, el encierro para Polín.

El espacio cerrado, configura en Crónica de un niño solo un elemento narrativo temático fundamental y se refuerza a través de las posiciones de la cámara en picado y contrapicado: el celador es una figura que se agiganta por efecto de la toma en contrapicado y la cámara en contrapicado nos muestra las escaleras del reformatorio donde se encuentra el celador, lo cual remite a una estructura visual asimilable al panóptico foucaultiano. Poder, vigilancia, disciplinamiento, control. La modalidad del encierro. La toma en picado de los chicos subjetiva la posición del celador en la apertura del filme, cuando las mujeres vienen a visitar a sus hijos se repite esta visión de panóptico. Estas madres que vienen del afuera también permanecerán dentro de la esfera de control establecida por el poder. La angulación y posición de la cámara en picado da cuenta de la mirada opresiva de la ley (Farina, 1993: 18) y a través de la posición en contrapicado se proyecta fuera del cuadro para la mirada de la víctima. El espacio del reformatorio se presenta como laberíntico, casi espiralado. Mientras que los pasillos de la villa aparecen como intersticios por los cuales es posible escapar del encierro, lo mismo sucede con el tragaluz por el que se escapa Polín. Toda la película se construye en base a la oposición dialéctica espacio abierto/ espacio cerrado, y sus derivados: espacio libre/espacio opresivo; espacio protector/ espacio amenazante. Estos pares se organizan a través de decisiones de puesta en escena, ubicación de la cámara, montaje y edición final.

La relación entre la luz y la sombra también conforma el espacio poético que Favio construirá a partir de Crónica de un niño solo pero que seguirá priorizando en los films sucesivos. Sombras y luz de día en los momentos en los que Polín juega con Fabián en un espacio libre. Interiores oscuros en el reformatorio. La noche en un espacio exterior sólo aparece con el motivo de una nueva "traición", ahora hacia un adulto amigable -Fabián- a quien Polín le roba el caballo. La sombra se utiliza para presentar la soledad y el encierro de los personajes. También funciona para dar cuenta de la multiplicidad de la red de poder: Polín encerrado y su sombra y la de los barrotes multiplicándose, ampliándose, encerrándolo aún más. La sombra del celador crece, es mayor a la figura humana real, se torna amenazadora. Por último, en una escena del reformatorio los chicos están "atrapados" entre el celador y su sombra en la pared.

El descenso a los infiernos de Nazareno las luces y sombras refuerzan una visión de tipo pictórica, una reelaboración de las escenas dantescas de El Bosco sobre el infierno y el purgatorio.

Si en Crónica de un niño solo el encuadre es una forma de tratamiento de los personajes y de la poética del espacio, en Nazareno Cruz y el lobo el montaje y el trucaje es la poética del espacio y del tiempo del propio cineasta. El trucaje y el montaje paralelo permiten a Favio armar "frescos o murales multicolores grandiosos" (Farina, op.cit.: 17). Los fundidos encadenados son utilizados para narrar el peregrinaje forzado de Nazareno, cambios abruptos de la luz sobre el mismo paisaje nos dan una noción artificial de la duración.

Los primeros planos se utilizan en ese mismo sentido (por ejemplo, a través de un travelling la imagen se amplia, el celador se presenta a través de la utilización de la sombra) El mismo recurso utilizado en una toma subjetiva de Polín (vemos sólo el rostro del chico al que le pega Polín) o bien un primer plano del rostro de este personaje mientras roba una billetera en el colectivo. Los primeros planos en Crónica de un niño solo aparecen, en general, para dar cuenta de elementos narrativos que tendrán una consecuencia determinada en la cadena de eventos, de esta forma, Favio reutiliza el recurso clásico de Hollywood para remarcar que habrá un desencadenante y para resaltar emociones.

La construcción de una poética 
propia es notoria, también, en la utilización del montaje, que a su vez configuran estos pares de organización espacial que se vienen señalando. La utilización de la elipsis puede observarse en el tramo que va desde el cachetazo al celador hasta la detención de Polín. En la escena de la violación, además de la elipsis anteriormente mencionada, aparecerá una apelación al simbolismo: la violación no se ve, si un plano de una paloma y de un cobayo. Nuevamente un elemento que permanecerá film tras film de Favio, los animales como acompañantes fieles (el caballo de Fabián en Crónica de un niño solo) o bien como metáforas (la paloma y el cobayo en Crónica de un niño solo y el lobo en Nazareno Cruz y el lobo).

El montaje paralelo también estructura la narrativa de la escena mencionada, lo que da cuenta, en el juego espacial que produce, la decisión de Polín de optar por la traición a su amigo.

Favio trabaja sobre todo con el diseño del cuadro, vaciando o recargando un segmento o ángulo, así algunas acciones transcurren en un sector del encuadre y en profundidad de campo, retomando los cortes abruptos usados junto con el planosecuencia (es lo que hace en la secuencia de la violación mientras que en la de la fuga alarga los planos-secuencia). No aparece la conmiseración, no se utiliza el ascetismo para apoyar reflexiones metafísicas sino más bien para mostrar -en el sentido de Daney (1998)-, como mostración de lo vivido y no como demostración. En el final, Polín y Nazareno están casi solos en el cuadro. Es el recurso del "valor desocupado" (Bresson, 1975) en el que un personaje escapa y deja un espacio vacío que luego vuelve a ocupar, remarcando la significación a través de la ausencia. El "valor desocupado" es evidente en Crónica de un niño solo mientras que en Nazareno Cruz y el lobo más que vaciamiento hay un cambio de encuadre y un exceso de uso del montaje paralelo, Nazareno solo sale del cuadro cuando aparecen los cielos o los pastizales. Favio trabaja, sobre todo, con el diseño del

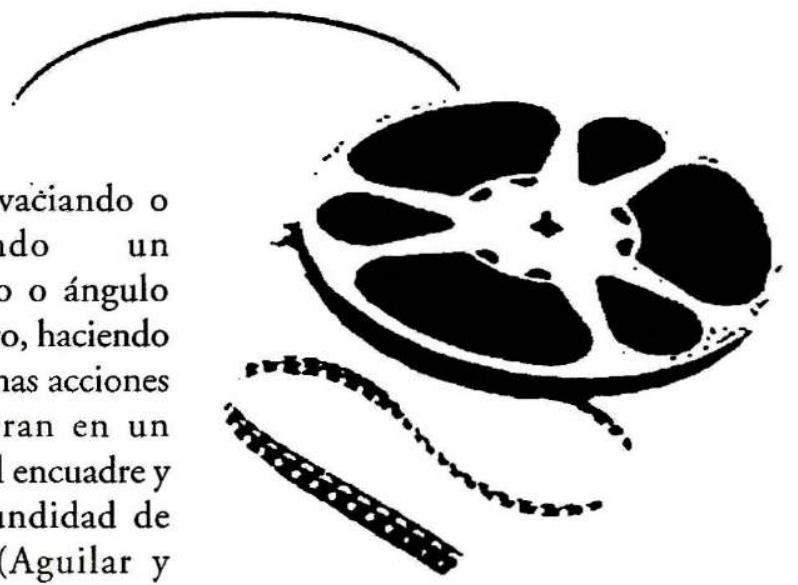

cuadro: vaciando o recargando un segmento o ángulo del cuadro, haciendo que algunas acciones transcurran en un sector del encuadre y en profundidad de campo (Aguilar y Oubiña, 1993).

Por último, señalamos que la escenografía de Crónica de un niño solo es más cercana al realismo que la de Nazareno Cruz y el lobo con sus colores saturados (azules, rojos y verdes) y trucos fotográficos (nubes en movimiento) que recuerdan la estética de Fellini y la de Antonioni.

En los dos filmes Favio asume la narración del espacio como una expresión de los sectores populares, un lugar para el devenir, con una estructura coral en la que los personajes principales y secundarios se relacionan por su ubicación en cuadro y por la repetición de los diálogos. Favio concibe la puesta en escena como una orquesta ejecutando una sinfonía: cada personaje, principal, secundarios o los extras tienen una cadencia y un diálogo, una posición el cuadro que crea el conjunto de la puesta en escena como planos simultáneos, como ejecució:s sincrónicas de instrumentos musicales.

A pesar de que los recursos formales y narrativos de Crónica de un niño solo y Nazareno Cruz y el lobo sean en gran medida y a simple vista divergentes, la poética es la misma: el espacio es producto de la tensión entre aspiraciones individuales y colectivas. Es una forma de poner en escena la sentencia de Buñuel: "Si en el neorrealismo los pobres son tan buenos y tan amados por Dios, para qué van a ser pobres" (apud en Farina, 1993: 1).

El uso del espacio es una de las maneras centrales en que Leonardo Favio posiciona su mirada. Es decir, su concepción ética, poética y política del cine. 


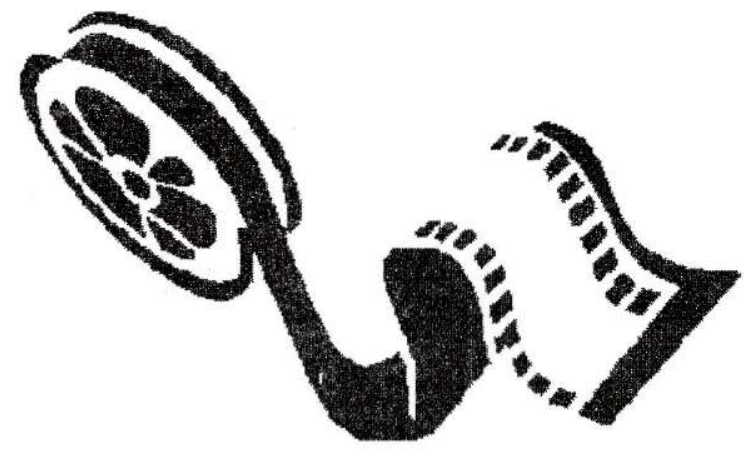

Una poetica del tiempo

El uso del sonido, de la música y del silencio tienen en la filmografía de Favio un valor especial: Crónica de un niño solo es un filme con quiebres entre sonido y silencio, un clima moroso que contrasta con el ritmo grandilocuente y la musicalización de casi todas las escenas en Nazareno Cruz y el lobo. El ritmo cinematográfico es para Favio tiempo y el tiempo es sonido.

La eliminación del sonido ambiente en Crónica de un niño solo (por ejemplo, en la escena del escape de Polín del reformatorio hay silencio hasta la caída de una lata y luego, pasos que quiebran el silencio) permite narrar a través de la ausencia de sonidos, la rutina de Polín en el reformatorio, es decir, el tiempo. El silencio, al igual que los diálogos breves y lacónicos, nos reenvía al vacío de acontecimientos (Wolf, 1993: 109) en este filme. A esta ausencia de acciones se suma la melancolía y la tristeza de la música de Verdi que aparece en la apertura del filme y que reaparecerá durante la violación del amigo y finalmente, en la detención de Polín. La música funciona entonces como confirmación de que no hay escapatoria para Polín, mientras que el silencio, aparece como anticipación de lo que ocurrirá. La música señala lo inevitable de los pequeños desgarros que constituirán el recorrido del personaje de Polín, una poética del tiempo (Ibidem) sobre las tragedias cotidianas.

En Nazareno Cruz y el lobo, en cambio, hay un uso clásico de la música que marca el tiempo dramático y las acciones grandilocuentes: el ritmo de la persecución del protagonista lo marca "Rigoletto" Verdi. La ópera se mezcla con temas populares como "Soleado" de Tacar y anticipan la tragedia de Nazareno, en el inicio de la cacería de este personaje convertido en lobo, Verdi se funde con los sonidos de los disparos y las tomas en cámara lenta. La reiteración del tema "Soleado"- cantado por Favio- indica que los amantes, Griselda y Nazareno, estarán juntos pero muertos. Sonido e imagen se funden en la tragedia popular y por eso la velocidad del filme disminuye. En el uso del ritmo musical en Nazareno Cruz y el lobo hay una política del exceso, una forma privilegiada de representación del radioteatro como deudor de la opereta. Asimismo, en este film no hay prácticamente secuencias sin sonido ambiente o sin musicalización.

Otro procedimiento que construye esta poética temporal es el de la repetición: la reiteración de un tiempo sin grandes sobresaltos en Crónica de un niño solo como una sinfonía de movimientos repetitivos que se organizan en una estructura coral: dos chicos juegan un partido de bolitas soplándolas, otro patea una pelota de goma con sus alpargatas y Polín no deja de dar vueltas. Los chicos del reformatorio "matan el tiempo".

La repetición en Nazareno Cruz y el lobo aparece a través de la fuga: el protagonista corre por el campo en cámara lenta y el tema "Soleado" indica que la tragedia se acerca, no hay salida para Nazareno. Las imágenes del cielo amenazador en Nazareno Cruz y el lobo y las escenas a media luz del reformatorio en Crónica de un niño solo refuerzan la antesala de un final que no será final, el espacio del campo o el del reformatorio es exponentes de un tiempo circular. El espacio, para Favio, es tiempo. La repetición es, según Bresson (1975), una de las características del "arte cinematográfico" como recurrencia de movimientos y comportamientos por oposición al "cine", teatral y representativo.

Las elipsis temporales son, también, recursos para la construcción de un tiempo repetitivo:

Nazareno y Griselda se encuentran por primera vez y a través de una elipsis los vemos en el baile del pueblo con el travelling giratorio que es el loitmotiv del filme. También la elipsis nos lleva a la 
confirmación de la unión entre los enamorados por vía indirecta: el diablo le cuenta a Nazareno que está maldito y que su transformación en lobizón es inminente porque se ha enamorado. En el caso de Crónica de un niño solo la elipsis nos lleva desde el cachetazo que Polín le da al celador en el reformatorio hasta su detención y el ingreso en el sistema judicial. La elipsis anticipa lo que será la nueva caída de Polín: el robo del caballo y la detención definitiva.

Los personajes de Favio están cercados por el tiempo que le roban, a la institución en el caso de Polín, y al destino, en el de Nazareno. Un tiempo prestado que está representado a través de una multiplicidad de elipsis.

Una diferencia notoria entre estos dos filmes: el tiempo en Nazareno Cruz y el lobo es fragmentario y se construye a través del montaje paralelo con un efecto de reiteración; mientras que en Crónica de un niño solo el tiempo es lento y continuo, a través de los planos-secuencia el tiempo se estira. La poética del tiempo (Wolf, 1993) en Nazareno Cruz y el lobo es sobre los grandes proyectos, tiene un sentido épico que sería imposible en Crónica de un niño solo. Durante la persecución de Nazareno el montaje paralelo refuerza la estructura coral, el llanto de Griselda en la casa de su padre, la espera en la penumbra y los rezos de la madre de Nazareno, Fidelia repite una fórmula mágica, la bruja Lechiguana que mira el cielo como si midiera el tiempo que le resta de vida al protagonista. El tiempo como pura espera del desenlace se relaciona en Nazareno Cruz y el lobo de su vinculación con el radioteatro en particular y con el folletín en general. La anticipación de las acciones y el preludio del desequilibrio son elementos canónicos en la cadena narrativa de estos géneros.

La concepción del tiempo, también, es indicio de la tragedia en Crónica de un niño solo por medio del plano-secuencia y del montaje paralelo. En la secuencia de la violación de su amigo, Polín está retozando y alternativamente aparece en la otra orilla la víctima acosada por victimarios, durante la persecución Polín continúa en la otra orilla y sólo después cruza en su búsqueda. Aquí "La marca de
Bresson es tan general como el uso del plano-secuencia" (Farina, op.cit.: 12). Hay un tiempo de espera, entre el paso del cigarrillo de uno de los chicos al otro. Aunque el procedimiento formal parezca semejante, porque hay cortes abruptos en el plano-secuencia de la violación del amigo de Polín, la elección estética y temática provoca un efecto de retardamiento del tiempo ${ }^{6}$.

El ritmo cinematográfico en Nazareno Cruz y el lobo y en Crónica de un niño solo es parte de la voz narrativa de Favio, su poética del tiempo (Wolf, op.cit.). La poética del tiempo de los filmes de Favio se funda en utilizar el movimiento al servicio de la temporalidad, la imagen no es movimiento sino "imagen-tiempo" (Deleuze, 1990). Favio reemplaza la búsqueda de movimiento en el cine por el tiempo, propone a la imagen como un eterno presente, un destino siempre trágico y desgarrado.

\section{Soledad, ley y desamparo}

La soledad, la ley y el desamparo son tres ejes temáticos que ligan a Crónica de un niño solo de un niño solo con Nazareno Cruz y el lobo. Tanto Polín como Nazareno están solos: Polín en un mundo que le es hostil, en una sociedad que margina a sus hijos más desprotegidos, los de la pobreza y la exclusión. Nazareno, está solo con su condena. Ambos son seres desamparados, en algún lugar héroes perdedores de algún modo trágicos, con un destino que pareciera inmodificable. La ley, la legalidad en lugar de ampararlos los expulsa, los estigmatiza, los ubica en el lugar de lo otro: el lobizón, en el caso de Nazareno; "la manzana podrida"' en el de Polín.

Otro de los temas centrales es el eje lealtad/traición, problemática habitual en la filmografía de Favio y que reaparece en todos sus filmes como parte de su cosmogonía. Este tópico cruza las relaciones de amistad, las de confianza, las de compromiso. En Crónica de un niño solo esta relación se construye entre Polín y su amigo, por un lado y entre Polín y Fabián, por el otro; en Nazareno Cruz y el lobo Cruz. El tema de la lealtad se jugará
${ }^{6}$ En la secuencia de la violación Favio reutiliza un recurso que estaba presente en una escena de Pickpocket (1959) de Robert Bresson. El plano-secuencia bressoniano se repite en la fuga de Polín como en Un condenado a muerte se escapa (1956).

${ }^{7}$ El celador le grita a Polin " Usted es la manzana podrida. Usted me los va a pudrir a todos!" 
entre Nazareno y el diablo, Nazareno y Fidelia y por supuesto, entre Nazareno y Griselda. La lealtad como principio rector de las relaciones sociales y la traición como posibilidad constante, al acecho permanente, y otras veces como realización concreta.

La filmografia de Favio constituye, a nuestro entender, una poética política que se sitúa en el margen de las corrientes descriptas tanto en su concepción estética, como en relación con las instancias de producción y distribución. Al igual que los exponentes del cine de intervención política presentará un mundo donde los pobres son centrales, pero en él no hay compasión, no hay exaltación de la pobreza, ni una contemplación dulcificada de la misma.

La de Favio es una mirada que padece junto a sus personajes, no frente a ellos. La suya es una mirada que padece, se salva o se hunde con las criaturas que crea. Pero que también se objetiva a través de los movimientos de cámara para observar a sus protagonistas sin dejar de ser una aproximación emocional. Un cine calificado de "pensamiento emocional" (Aguilar y Oubiña, 1993), que aprehende el mundo a partir de la emoción. La combinación de los elementos de la cultura popular y de la cultura "alta" tampoco es fuente de una mirada distante y paródica ni contemplativa, es la recuperación de las tradiciones populares, como lo demuestra la decisión por adaptar el reconocido radioteatro Nazareno Cruz y el lobo. Ese "pensamiento emocional" es lo que acerca a Favio a una poética cinematográfica la del llamado "cine de poesía": "el autor se construye un personaje que habla una lengua inventada para explicar su propia interpretación del mundo" (Pasolini, 1970) a través del discurso indirecto.

En Crónica de un niño solo la presentación de los pobres y la manera en que el autor abordará su mundo será fundacional del resto de su filmografía. Favio no teme presentar la crueldad de los pobres, dirá en uno de los reportajes que se le han hecho: "la pobreza no es un estado de gracia sino un estado de violencia". Varias son las temáticas que se entrecruzan en el filme para dar cuerpo a esta configuración poética de la pobreza, del desamparo de las clases populares y, dentro de esta, de los más desamparados: los nifios solos. La soledad y la inermidad del personaje protagónico. Su deambular en un mundo sin transformaciones radicales: castigo, lealtad, amistad, crueldad. Y por supuesto, la ley y la legalidad, lo institucional y la vida cotidiana: humillación y resistencia.

La ley y la legalidad tienen un peso primordial en Crónica de un niñosolo, todo se juega entre la institucionalidad de lo legal (cárcel, reformatorio, policía, juez) y el afuera, lo marginal, la pobreza, lo prohibido. La ley es absurda y las instituciones son falaces e inútiles. Crónica de un niño solo puede entenderse junto con las otras obras de la filmografía de Favio como alegoría de la ley (Aguilar y Oubiña, op.cit.).

En todo caso, el enfrentamiento social está dado por su ausencia, no es más que el indicio, no es la explicación de la situación de los sectores populares. Si la burguesía es el oponente (el juez solo aparece para dar cuenta de la inutilidad de la ley), la pequeńa burguesía aparece para dar cuenta de la ley (celador, juez y el policía). Los forcejeos (con celadores o policías) no remarcan la distancia desde la posición de Polín sino algo que es del orden de lo ajeno.

En ese sentido es interesante remarcar la oposición entre la imagen y la perspectiva burocrática que se plantea en la escena donde el representante de la ley entra a la villa. El lenguaje leguleyo se contrapone a las imágenes y a la oralidad.

Crónica de un niño solo y Nazareno Cruz y el lobo son filmes que cuestionan lo legal instituido (se quiebran las expectativas sociales en Crónica de un niño solo y las familiares en Nazareno Cruz y el lobo). Polín y Nazareno son personajes desafiantes y rebeldes pero en situaciones de inermidad, ambos se quedan solos, uno es encarcelado y otro muere. Favio impone una legalidad diferente a sus personajes que se debate, como ya hemos dicho, entre la traición y la lealtad: Polín traiciona a su amigo de la villa y a Fabián y Nazareno es traicionado por su propio destino y por el padre de Griselda. La lealtad de Polín es hacia esos mismos personajes y la de 
Nazareno hacia Griselda.

A pesar de que la muerte es la presencia misma de lo trágico, hay lealtades hacia Nazareno que en el universo de Polín no son posibles: el diablo es fiel a la promesa que le hace a Nazareno, Fidelia es el lazo entre el protagonista, oculto en el campo, y Griselda. Sin embargo, ni uno ni otro se salvarán. Es el destino de quienes quedaron al margen de toda legalidad instituida: los solos -sean niños o adultos; los desamparados por pobreza, diferencia o excepcionalidad. Es decir, los fuera de la ley. Polín volverá a la cárcel y en ese ir mirará desafiando a la cámara, mirará también a los espectadores, logrando a través de un efecto de distanciamiento quitarle al espectador la posibilidad de piedad contemplativa. Por su parte Nazareno es asesinado, y es fácil concluir que el amor no vence al odio.

Dos películas diferentes y similares que forman parte de una misma poética y que convocan a un mismo tipo de reflexión: la emocional.

\section{Consideraciones finales. Una poética política}

Leonardo Favio, construye un universo cinematográfico a su medida, con ejes temáticos recurrentes y un estilo absolutamente definido que puede observarse a lo largo de toda su obra y donde Crónica de un niño solo constituye el "punto de partida de la constitución de una poética” (Aguilar y Oubiña, op.cit: 30). Una búsqueda poética que comienza en Crónica de un niño solo... y proseguirá en los filmes posteriores la cual plantea la posibilidad de crear un relator desde y con los sectores populares: una poética política popular.

La filmografía de Favio retoma el "antiguo tropo de la indiferencia del mundo" (Farina, 1993: 21) frente a la muerte y al fracaso de perdedores solitarios que habían sido expulsados de las narraciones hegemónicas. La tragedia marca el destino de los personajes de Crónica de un niño solo y Nazareno Cruz y el lobo y su mirada hacia sus protagonistas no es ni complaciente ni irónica, se trata de una mirada que comparte el destino del héroe, su

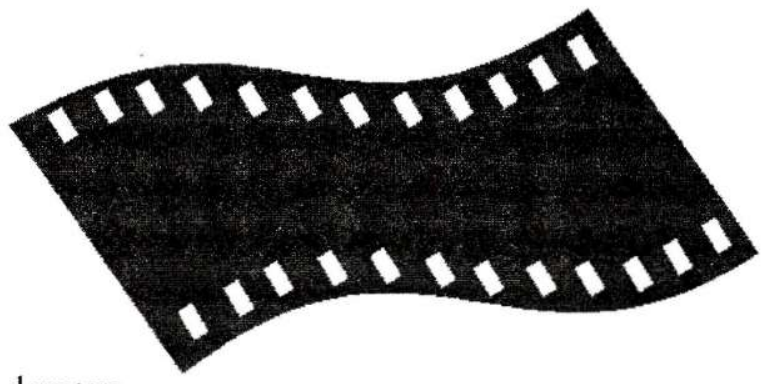

derrotero.

La dimensión trágica (desde una visión tradicional se puede concebir como irresoluble) o bien como aquello que da cuenta de un pathos, que vuelve a introducir lo que había sido previamente expulsado por la ley de la discusión pública.

Favio reintroduce las tragedia de los sectores populares en relatos de soledad, sin conmiseración. Nazareno y Polín, buscan una salida incierta pero lo único que logran es retrasar un tanto lo inevitable. Se trata de personajes que aparecen siempre como ajenos al lugar donde están, no pertenecen a ningún lugar. Los desplazamientos en Nazareno Cruz y el lobo y Crónica de un niño son más que recorridos: representan el intento de huida que inevitablemente fallará. Nazareno atraviesa el campo, un espacio que parece siempre igual, como si su recorrido fuese circular, como sucede en la historia de Polín que termina donde comenzó, en el reformatorio. Si Polín es la "manzana podrida" como le dice el juez, Nazareno es digno de piedad "si has elegido entre el amor y el oro" profetiza la Lechiguana. Los primeros planos son impiadosos en Crónica de un niño solo, un efecto que Favio logra en Nazareno Cruz y el lobo a través de los planos generales del cielo y del campo.

La ley (el celador, el juez y el policía) en Crónica de un niño solo enfrenta a Polín como si su destino estuviese marcado. El enfrentamiento social en Crónica de un niño solo es ausencia, opera por indicios: forcejeos, intrusiones, silbatos que detienen el tiempo. Por el contrario, en Nazareno Cruz $y$ el lobo el enfrentamiento es parte de la escenificación, no hay lobo si no hay cazador. 
La amalgama entre lo culto y lo popular quizá pueda servir como eje para ubicar la poética de Leonardo Favio. Su cine se desliza cómodo entre ambos polos: contra la cultura elitista y contra la estandarización de la cultura masiva. De allí la elección de Crónica de un niño solo y de Nazareno Cruz y el lobo para dar cuenta de la unicidad de la obra, jugar un contrapunto entre ambas películas facilita la visualización de este deslizamiento mencionado.

La apropiación de lo popular, al mismo tiempo, constituye una operación de resistencia (Aguilar y Oubiña, op.cit.) organizando una historia desde los márgenes hacia el centro. Una poética de los márgenes, un uso político de los géneros y una poética cinematográfica ligada a historias marginales.

Durante las década de '60 y '70 la relación arte y política era central en los debates culturales e intelectuales y aunque Favio no estuvo inserto en estas discusiones no puede negarse el carácter profundamente político de sus películas de ficción.

Hay quienes señalan que sólo la asunción de una posición estrictamente política en la obra fílmica de Favio está presente a partir de Juan Moreira o que, a lo sumo podría reconocerse una transición en El romance del Aniceto y la Francisca. Sostenemos que la unicidad de la filmografía de Favio está dada por coincidencias temáticas, narrativas y estéticas, a partir de Crónica de un niño solo en adelante.

A pesar del exceso musical y del recargamiento del cuadro, Nazareno Cruz y el lobo como Crónica de un niño solo es una escritura en los bordes, el interés no está en el centro del cuadro sino en los márgenes (Wolf, 1993: 111). Es una concepción política de los márgenes y de cómo los sectores populares "llenan" el cuadro. Un cine de resistencia, profundamente político donde la sobriedad no tiene lugar ni en la estética, ni en la política que plantea. Un cine en donde lo emocional es la vía de acceso a lo político.

Se ha señalado que mientras Crónica de un niño solo resalta la salida individual y sus limitaciones, Nazareno Cruz y el lobo
- como Juan Moreira- son elegías a las soluciones colectivas (Farina, 1993; Oubiña y Aguilar, 1993), sin embargo, el par lealtad/traición se superpone en la filmografía de Favio a cualquier posibilidad de proyecto colectivo o individual. No estamos frente a una visión sobria de la política, ni siquiera en Crónica de un niño solo, como tampoco es una concepción ascética de la estética. El barroquismo del encuadre de este filme es también el barroquismo de la política, la diferencia estético-política con Nazareno Cruz y el lobo no está en la contraposición sino en la asunción, el festejo y la grandilocuencia de esa mirada estética, barroca, sobre la política. Como clamaba Pasolini, el cine de Favio es "un cine de poesía" (1970) no de prosa. Leonardo Favio construye una poética del espacio, del tiempo, de la política: la sinfonía dẹ una estética.

\section{Abstract}

The objective of this work is to analyze how in Crónica de un niño solo and in Nazareno Cruz y el lobo Leonardo Favio constructed a unitary artistic work and proposes a politic poetic of films. In doing so, we identify a poetic of space and a poetic of time. The concepts of "loneliness", "law" and "abandonment" also help to understand the filmmaking of Leonardo Favio and the articulation of these into the mise en scène and the space and temporal poetics.

Keywords: cinema - aesthetic - political

Bibliografia

AGUILAR, G. y OUBIÑA, D. El cine de Leonardo Favio. Buenos Aires: Nuevo Extremo, 1993.

AGUILAR, G. Lautaro Munia. Centro Editor de América Latina, Buenos Aires, 1994.

BRESSON, R. Notes sur le cinématographe. París : Gallimard, 1975.

DANEY, S. Perseverancia. Buenos Aires: Ediciones Tatanka, 1998.

DELEUZE, G. La imagen-tiempo. Estudios sobre cine 2. Paidós; Barcelona, 1990.

FARINA, A. Leonardo Favio. Colección Los directores de cine argentino. Buenos Aires: CEAL, 1993.

PASOLINI, P. P. Cine de poesía contra Cine de prosa. Barcelona: Anagrama, 1970.

TORRE NILSSON, L. “La imagen narra” [1963]. In: Torre Nilsson por Torre Nilsson. Selección y prólogo de Jorge Miguel Couselo. Buenos Aires: Editorial Fraterna, 1985, p. 71-73.

WOLF, S. "Leonardo Favio: intuición del tiempo". In: WOLF, S. Cine argentino. La otra historia. Buenos Aires: Editorial Letra Buena, 1993, p. 103-115. 